\title{
SOEP
}

SOEPpapers

on Multidisciplinary Panel Data Research

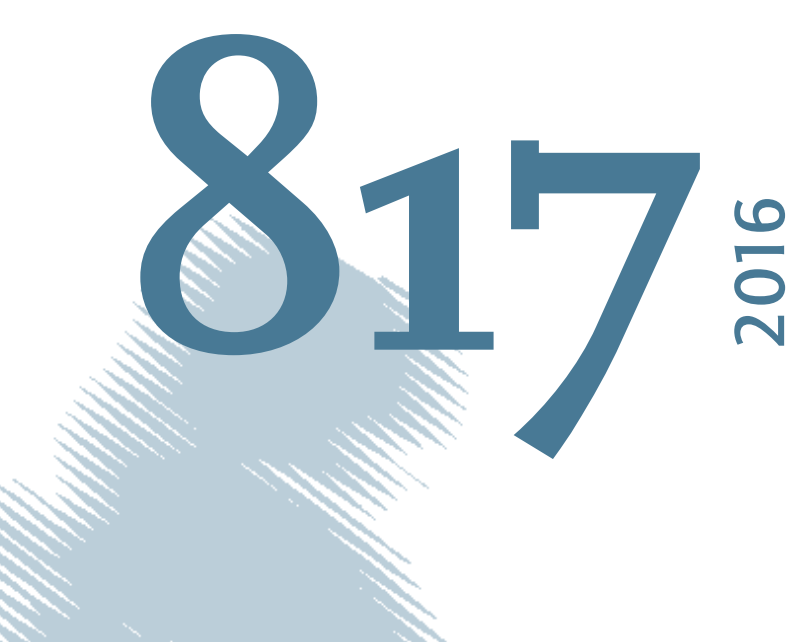

$\mathrm{AlN}^{-}$

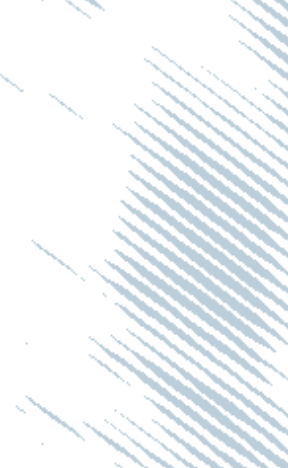

Nan

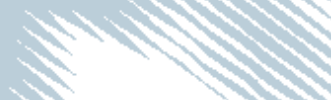

(5)

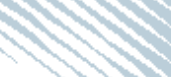

\section{How Much Can We Trust Maternal Ratings of Early Child Development in Disadvantaged Samples?}


This series presents research findings based either directly on data from the German SocioEconomic Panel study (SOEP) or using SOEP data as part of an internationally comparable data set (e.g. CNEF, ECHP, LIS, LWS, CHER/PACO). SOEP is a truly multidisciplinary household panel study covering a wide range of social and behavioral sciences: economics, sociology, psychology, survey methodology, econometrics and applied statistics, educational science, political science, public health, behavioral genetics, demography, geography, and sport science.

The decision to publish a submission in SOEPpapers is made by a board of editors chosen by the DIW Berlin to represent the wide range of disciplines covered by SOEP. There is no external referee process and papers are either accepted or rejected without revision. Papers appear in this series as works in progress and may also appear elsewhere. They often represent preliminary studies and are circulated to encourage discussion. Citation of such a paper should account for its provisional character. A revised version may be requested from the author directly.

Any opinions expressed in this series are those of the author(s) and not those of DIW Berlin. Research disseminated by DIW Berlin may include views on public policy issues, but the institute itself takes no institutional policy positions.

The SOEPpapers are available at http://www.diw.de/soeppapers

\section{Editors:}

Jan Goebel (Spatial Economics)

Martin Kroh (Political Science, Survey Methodology)

Carsten Schröder (Public Economics)

Jürgen Schupp (Sociology)

Conchita D'Ambrosio (Public Economics)

Denis Gerstorf (Psychology, DIW Research Director)

Elke Holst (Gender Studies, DIW Research Director)

Frauke Kreuter (Survey Methodology, DIW Research Fellow)

Frieder R. Lang (Psychology, DIW Research Fellow)

Jörg-Peter Schräpler (Survey Methodology, DIW Research Fellow)

Thomas Siedler (Empirical Economics)

C. Katharina Spieß ( Education and Family Economics)

Gert G. Wagner (Social Sciences)

ISSN: 1864-6689 (online)

German Socio-Economic Panel (SOEP)

DIW Berlin

Mohrenstrasse 58

10117 Berlin, Germany

Contact: Uta Rahmann | soeppapers@diw.de

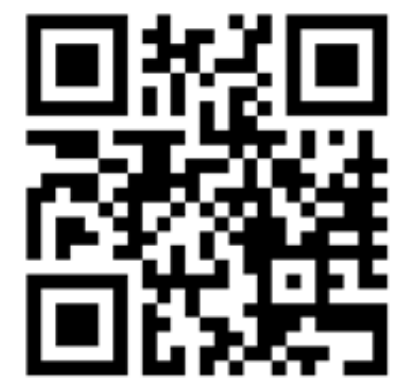




\title{
How Much Can We Trust Maternal Ratings of Early Child Development in Disadvantaged Samples?
}

\author{
Malte Sandner**, Tanja Jungmann ${ }^{\S}$ \\ * NIW Hannover, Königstrasse 53, 30175 Hannover \\ $\S$ Universität Rostock August-Bebel-Strasse 28, 18051 Rostock
}

January 2016

\begin{abstract}
An increasing number of panel studies use short screening questionnaires to assess infant development. Although some research examines the validity of screening questionnaires for middleclass families, knowledge about their accuracy in disadvantaged households is scarce. This paper validates a short screening questionnaire included in the German Socio-Economic Panel (SOEP) with the Bayley Scales for Infant Development (BSID) as an external criterion with a disadvantaged population. The results reveal significant correlations between the screening questionnaire ratings and the BSID scores for disadvantaged mothers. However, the concordance of maternal ratings and test results decreased in mothers with multiple risk burdens.
\end{abstract}

JEL-Classification: J13, C42, C91

Keywords: Child Development, Validation of Survey Measures

\footnotetext{
* Forthcoming in Economics Letters. We are grateful to the editor Costas Meghir, and an anonymous referee, Stephan Thomsen, Katharina Spieß, and Daniel Schnitzlein, for for their helpful comments and suggestions. Financial support by the German Federal Ministry for Family, Seniors, Women and Youth (BMFSFJ), the Saxony Social Ministry, the TUI Foundation, and the Foundations Dürr and Reimann-Dubbers is gratefully acknowledged.
} 


\section{Introduction}

Recent evidence from economic research underlines the crucial role of early childhood in lifelong human capital accumulation (e.g., Cunha and Heckman, 2007; Almond and Currie, 2011). Many economists claim that policies for disadvantaged families starting in early childhood are efficient to reduce poverty and inequality (e.g., Heckman and Masterov, 2007). To understand the mechanisms of the effects of these policies, it is important to consider both, long-term outcomes, such as income or grades, and shortterm outcomes, such as infant development. Field experiments offer the opportunity to assess infant development using tests administered by professional examiners, with the Bayley Scales for Infant Development (BSID; Bayley, 1993) considered the "gold standard". However, developmental tests are costly to conduct and difficult to administer in large panel studies. Therefore, panel studies such as the German Socio-Economic Panel Study (SOEP, Wagner et al., 2007) or the National Longitudinal Survey of Children and Youth (NLSCY, Statistics Canada, 2001) use less time and cost intensive screening questionnaires (SQs) in which the caregiver rates the infants development.

However, measuring children's skills by asking the parents may be accompanied with many threats to validity. Caregivers can be positively or negatively biased in their perception of their children, may give socially desired answers, or may report developmental achievements only because they are asked for (e.g., Schwarz, 1999). Furthermore, child development is a highly dynamic process with large individual variation. While some evidence indicates that these threats only slightly bias the screening scores in average populations (e.g., Johnson et al., 2004), research has not determined whether this finding also applies to disadvantaged mothers, who are the main target population for early childhood interventions. The described threats may be more severe for disadvantaged mothers because they are often less knowledgeable about the milestones of child development. Additionally, they are more often socially isolated and thus have limited occasions to compare their own children's development to that of age-equivalent children. Even if they have a functioning social network, these mothers are often too burdened with daily crises and existential problems to fully realize developmental delays in various domains of child development.

This paper examines the validity of the SOEP-SQ (see Schmiade et al., 2008, for de- 
tailed description) in a sample of psychosocially disadvantaged mothers. The mothers exhibit between one and 12 social risk factors (e.g., low education, teenage pregnancy, isolation, experiences of violence or health problems). For validation, infants were screened using the SOEP-SQ and were tested using the BSID-II (German version by Reuner et al., 2007) as an external criterion. The results revealed significant correlations between the overall disadvantaged mothers' SOEP-SQ ratings and the BSID-II scores $(\mathrm{r}=0.35-0.56)$. We found that the concordance between the maternal ratings and the test results is lower for mothers with five or more risk factors than for mothers with less than five risk factors, although our sample size lacks power to show that these differences are significant. Overall, the results indicate that SQs draw a valid and reliable picture of child development, also in a disadvantaged sample. However, studies evaluating childhood policies for families with multiple risk factors should be cautious when using SQ results.

\section{Measuring Child Development}

Psychologists distinguish between two procedures to measure child development: screening and tests. Following the definition of the American Academy of Child and Adolescent Psychiatrists, screening involves the identification of current behavioral health or developmental status. In the screening procedure, developmental achievement in various domains (mental, psychomotor, behavior, and language) is typically documented using a standardized questionnaire. The family member or caregiver is expected to be a reliable source who knows the child well. Typically, the screening is quick and easy to administer and score. In contrast, testing is a more comprehensive process, as it involves the family and evaluates the strengths and difficulties of the child and the family in all life domains. A qualified individual with the appropriate credentials required by the licensing authority conducts the assessment of developmental status.

The SOEP-SQ is a short version of the Vineland Adaptive Behavior Scale (VABS; Sparrow et al., 2005), which is a screening procedure that obtains a parent's report of the child's adaptive behavior from one month of age through adolescence. Parents are asked to indicate whether their child always (2), sometimes (1), or never (0) demonstrates age-normed adaptive behaviors in four critical domains of functioning 
(communication, daily living skills, motor skills, and socialization). The interview contains 297 items and requires 30 to 60 minutes. The SOEP uses a modified short version of the VABS with the four subscales of "Speaking", "Everyday Skills", "Movement", and "Social Relationships" for infants between 24 to 36 months of age. This version includes a total of 20 items that have not been validated using external criteria. ${ }^{1}$

In contrast to the screening approach, the BSID-II is an examiner-administered test of infant development that assesses the mental abilities and psychomotor abilities of infants between the ages of one and 42 months. Mental abilities include perceptual acuities, acquisition of object constancy, memory, learning and problem solving, nonverbal and verbal communication, complex language, and abstract thinking. Psychomotor abilities are defined as the degree of body control, large muscle coordination, fine motor skills of the hands and fingers, dynamic movements, postural imitation, and the ability to recognize objects by the sense of touch with different items. The BSID-II comprises one scale to assess the mental abilities (Mental Development Index, MDI) and another scale to evaluate the psychomotor abilities (Psychomotor Development Index, PDI).

In conducting the BSID-II, the examiner presents a series of play materials or pictures to the child. She provides brief instruction for each task and observes and documents whether the child is able to solve it. The test sessions are videotaped and scored after the interview by a developmental psychologist. Raw scores for each subtest are summed and transformed into standard scores (MDI and PDI) with a mean of 100 and SD of 15. Because of the comprehensive and appropriate content, construct, and criterion validity, the BSID-II represents the "gold standard" of neurodevelopmental assessment in infancy and toddlerhood (e.g., Tylenda et al., 2007). Regarding predictive validity, most evidence refers to the MDI. In their literature review, Fryer and Levitt (2013) show that the average correlation between MDI and future IQ is approximately 0.3 at 9 years of age. For Germany in particular, Coneus et al. (2012) find a positive correlation between MDI and high school graduation. Less is known about the predictive validity of PDI.

\footnotetext{
${ }^{1}$ Appendix I provides the full text (English translation) of these SOEP screening questions (TNS Infratest Sozialforschung, 2015).
} 


\section{Data}

We used data from the evaluation of the Pro Kind home visiting program to determine the validity of the SOEP-SQ. Pro Kind is an early childhood intervention in which 755 psychosocially disadvantaged first-time mothers and their families received home visits from pregnancy until the child's second birthday. Participating mothers exhibited between one and 12 social risk factors and lived in a household that received social welfare benefits or unemployment compensation, had an income as low as social welfare benefits, and/or was over-indebted. Only mothers between the 12 th and 28 th weeks of pregnancy were affiliated with the project between November 2006 and December 2009. Pro Kind is located in three German federal states (two in West and one in East Germany). Jungmann et al. (2009) and Sandner (2013) provide detailed information about the program and the characteristics of the sample.

An interdisciplinary research team administered the BSID-II at six, 12 and 24 months after the child was born. Additionally, biannual telephone interviews surveyed maternal income, employment, fertility and health. The telephone interview conducted shortly after the second birthday of the child contained the SOEP-SQ. The BSID-II and SOEP-SQ were conducted at approximately the same time but in two different interviews, thus minimizing problems of induced responses.

Table 1: Descriptive Statistics for the SOEP-SQ, BSID-II and Sample Characteristics

\begin{tabular}{|c|c|c|c|c|c|}
\hline & Mean & $\mathrm{SD}$ & Min & Max & $\mathrm{N}$ \\
\hline \multicolumn{6}{|l|}{$S O E P-S Q$} \\
\hline Overall Value & 27.44 & 5.40 & 11 & 40 & 158 \\
\hline Speaking & 7.12 & 2.08 & 2 & 10 & 164 \\
\hline Everyday Skills & 5.66 & 2.09 & 1 & 10 & 164 \\
\hline Movement & 6.80 & 1.64 & 2 & 10 & 162 \\
\hline Social Relationships & 7.88 & 1.80 & 3 & 10 & 163 \\
\hline \multicolumn{6}{|l|}{$B S I D-I I$} \\
\hline MDI & 88.90 & 15.69 & 50 & 128 & 154 \\
\hline PDI & 95.65 & 14.64 & 50 & 125 & 136 \\
\hline \multicolumn{6}{|l|}{ Demographic Factors } \\
\hline Age of the Child BSID in Months & 25.07 & 0.98 & 23.3 & 28.8 & 166 \\
\hline Age of the Child VABS in Months & 25.85 & 0.89 & 23.0 & 27.0 & 166 \\
\hline Child Gender ( $1=$ Boy) & 0.47 & 0.50 & 0 & 1 & 166 \\
\hline Age of the Mother at Birth in Years & 23.46 & 4.77 & 15.4 & 40.5 & 166 \\
\hline Educational Background & 2.03 & 1.53 & 1 & 6 & 165 \\
\hline Socioeconomic Risk Factors & 5.54 & 2.28 & 1 & 12 & 166 \\
\hline
\end{tabular}

Notes: Socioeconomic Risk Factors refer to the sum of maternal risk factors at the time of affiliation with the Pro Kind intervention. Overall, 19 socioeconomic risk factors were defined. In the educational background variable the lowest category presents no graduation or graduation from school, but no vocational education. The highest category presents university degree or conferral of a doctorate. 
Table 1 shows the descriptive statistics of the sample that we used to validate the SOEP-SQ. ${ }^{2}$ The first rows present the outcomes for the SOEP-SQ and BSID-II. Pro Kind children scored lower than comparable children on the SOEP-SQ (Schmiade et al., 2008), and below the norm of 100 on the MDI and PDI. The last rows in Table 1 present the demographic factors of the children and the mothers. The children were approximately the same average age when they were tested with the BSID-II and when their mothers answered the SOEP-SQ. At their first child's birth, the mothers were young, had a low socioeconomic status indicated by a mean of 5.4 risk factors and a low educational background with $60 \%$ of the mothers in the lowest education group. These characteristics are potential obstacles to child development, as reflected in the children's low scores on the BSID-II scales and the SOEP-SQ maternal ratings. Results from multivariate regressions reveal that in particular a higher value at the education scale is positively correlated with both the SOEP-SQ and the BSID-II, indicating that the SOEP-SQ is suitable to detect unfavorable child development resulting from reduced stimulating environmental conditions.

\section{Methods}

We used Pearson's correlations between SOEP-SQ and BSID-II to test whether the SOEP-SQ measures what it intends to measure (construct validity). ${ }^{3}$ Because the SOEP-SQ and BSID-II assess partly the same constructs and partly different constructs, we were also able to test for high correlations between the BSID-II scales measuring the same construct (concurrent validity) and for low correlations between scales measuring different constructs (discriminant validity). We expected the highest correlations between the BSID-II MDI and the SOEP-SQ "Speaking" scale and between the BSID-II PDI and the SOEP-SQ "Movement" scale.

In the next step, we divided the sample into two groups of mothers with more than five and fewer than five risk factors because we expected more disadvantaged mothers to be less skilled in accurately rating the developmental status of their children. The results changed only slightly if the cut-off point was set to include one more or one

\footnotetext{
${ }^{2}$ Children were included in the sample if their mothers answered the SOEP-SQ when their child's age ranged from 23 to 27 months, resulting in a sample of 166 children.

${ }^{3} \mathrm{We}$ also used multivariate regression with maternal demographic characteristics as controls, leading to similar results.
} 
less risk factor.

\section{Results}

Table 2 summarizes the main results of the analysis. The correlations between the "Overall" SOEP-SQ value and the MDI and PDI scores were significant, with closer relationships with MDI than with PDI. As expected, MDI was more strongly correlated with the "Speaking" subscale than with the other scales. The correlation between the "Movement" scale and the PDI was close, as expected, but the correlation with the "Social Relationships" scale was even stronger.

Table 2: Correlation between SOEP-SQ and BSID-II

\begin{tabular}{lcccc}
\hline \hline & \multicolumn{2}{c}{ BSID-II, MDI } & \multicolumn{2}{c}{ BSID-II, PDI } \\
SOEP-SQ & $\mathrm{r}$ & $\mathrm{N}$ & $\mathrm{r}$ & $\mathrm{N}$ \\
\hline Overall Value & $0.487^{* * *}$ & 146 & $0.375^{* * *}$ & 129 \\
Speaking & $0.561^{* * *}$ & 152 & $0.192^{*}$ & 134 \\
Everyday Skills & $0.170^{*}$ & 152 & $0.241^{* *}$ & 134 \\
Movement & $0.259^{* *}$ & 150 & $0.330^{* * *}$ & 133 \\
Social Relationships & $0.362^{* * *}$ & 146 & $0.340^{* * *}$ & 133 \\
\hline \hline
\end{tabular}

Notes: $\mathrm{r}$ represents Pearson's correlation coefficients. ${ }^{*} \mathrm{p}<0.05,{ }^{* *} \mathrm{p}<0.01,{ }^{* * *} \mathrm{p}<0.001$

When the sample was divided into groups of more than five and five or fewer risk factors, the correlations were higher for the less disadvantaged subsample (Table 3). In the lower-risk sample, the correlation between MDI and "Speaking" increased up to 0.663 , and the correlation between PDI and "Movement" was higher than the correlations among the other scales. In the higher-risk group, the correlations remained significant but were smaller. However, the differences between the low- and high-risk groups are almost all insignificant and completely insignificant when adjusting for multiple testing. We also split the sample into a higher and lower education group, resulting in reduced correlations in the lower education group. Other characteristics, such as maternal age or child gender, did not influence the correlations.

\section{Conclusion}

This article examined how much we can trust in maternal ratings of infants' and toddlers' skills in disadvantaged populations. We assessed the construct validity of a 
Table 3: Correlation between SOEP-SQ and BSID-II by Socioeconomic Risk Factors

\begin{tabular}{|c|c|c|c|c|c|}
\hline \multirow[b]{2}{*}{ SOEP-SQ } & \multicolumn{2}{|c|}{$\begin{array}{c}\text { BSID-II, MDI } \\
\text { Five or fewer risk factors }\end{array}$} & \multicolumn{2}{|c|}{$\begin{array}{c}\text { BSID-II, MDI } \\
\text { More than five risk factors }\end{array}$} & \multirow[t]{2}{*}{ Diff. p-value } \\
\hline & $\mathrm{r}$ & $\mathrm{N}$ & $\mathrm{r}$ & $\mathrm{N}$ & \\
\hline Overall Value & $0.555^{* * *}$ & 74 & $0.429 * * *$ & 72 & 0.324 \\
\hline Speaking & $0.663^{* * *}$ & 75 & $0.471^{* * *}$ & 77 & 0.083 \\
\hline Everyday Skills & 0.041 & 77 & $0.283^{*}$ & 75 & 0.131 \\
\hline Movement & $0.330^{* *}$ & 77 & 0.187 & 73 & 0.357 \\
\hline \multirow[t]{2}{*}{ Social Relationships } & $0.465^{* * *}$ & 76 & $0.269^{*}$ & 75 & 0.170 \\
\hline & \multicolumn{2}{|c|}{$\begin{array}{c}\text { BSID-II, PDI } \\
\text { Five or fewer risk factors }\end{array}$} & \multicolumn{2}{|c|}{$\begin{array}{c}\text { BSID-II, PDI } \\
\text { More than five risk factors }\end{array}$} & Diff. p-value \\
\hline SOEP-SQ & $\mathrm{r}$ & $\mathrm{N}$ & $\mathrm{r}$ & $\mathrm{N}$ & \\
\hline Overall Value & $0.445^{* * *}$ & 61 & $0.341^{* *}$ & 68 & 0.495 \\
\hline Speaking & 0.173 & 62 & 0.208 & 72 & 0.837 \\
\hline Everyday Skills & $0.308^{*}$ & 64 & 0.200 & 70 & 0.514 \\
\hline Movement & $0.461^{* * *}$ & 64 & $0.256^{*}$ & 69 & 0.183 \\
\hline Social Relationships & $0.308^{*}$ & 63 & $0.374^{* *}$ & 70 & 0.674 \\
\hline
\end{tabular}

Notes: $r$ represents Pearson's correlation coefficients. "Diff. p-value" shows the significance level of the difference between the correlation coefficients in the two risk samples. ${ }^{*} \mathrm{p}<0.05,{ }^{* *} \mathrm{p}<0.01,{ }^{* * *} \mathrm{p}<0.001$

short screening of infant development used by the SOEP with the BSID-II as external criterion. The results indicate that short screenings of infants' and toddlers' adaptive behavior can draw a reasonable picture of infant development even in a socially disadvantaged sample. Only ratings from mothers with multiple risk factors should be handled with greater caution. Since our sample size was small, especially the differences across risk groups should reexamined in a larger sample. We recommend researchers who are interested in assessing the construct of mental development that is correlated with later school success to use the subscales "Speaking" and "Social Relationships" in the SOEP-SQ and other SQs. 


\section{References}

Almond, D. and J. Currie (2011). Human Capital Development before Age Five. In Orley Ashenfelter and David Card (Ed.), Handbook of Labor Economics, pp. 13151486. Elsevier.

Bayley, N. (1993). Manual for the Bayley Scales of Infant Development (2nd Edition). San Antonio: Psychological Corporation.

Coneus, K., M. Laucht, and K. Reuß (2012). The Role of Parental Investments for Cognitive and Noncognitive Skill Formation-Evidence for the First 11 Years of Life. Economics \& Human Biology 10(2), 189-209.

Cunha, F. and J. Heckman (2007). The Technology of Skill Formation. American Economic Review 97(2), 31-47.

Fryer, R. G. and S. D. Levitt (2013). Testing for Racial Differences in the Mental Ability of Young Children. American Economic Review 103(2), 981-1005.

Heckman, J. J. and D. V. Masterov (2007). The Productivity Argument for Investing in Young Children. Review of Agricultural Economics 29(3), 446-493.

Johnson, S., N. Marlow, D. Wolke, L. Davidson, L. Marston, A. O'Hare, and Peacock, Janet and Schulte, Jane (2004). Validation of a Parent Report Measure of Cognitive Development in very Preterm Infants. Developmental Medicine 8 Child Neurology 46, 389-397.

Jungmann, T., Y. Ziert, V. Kurtz, and T. Brand (2009). Preventing Adverse Developmental Outcomes and Early Onset Conduct Problems through Prenatal and Infancy Home Visitation: The German Pilot Project Pro Kind. European Journal of Developmental Science 3(3), 292-298.

Reuner, G., J. Rosenkranz, J. Pietz, and R. Horn (2007). Bayley Scales of Infant Development II (BSID-II), German Edition. Frankfurt/M: Hartcourt Test Services.

Sandner, M. (2013). Effects of Early Childhood Intervention on Child Development and Early Skill Formation. Evidence from a Randomized Controlled Trial. Hannover Economic Papers 518. 
Schmiade, N., C. K. Spiess, and W. Tietze (2008). Zur Erhebung des adaptiven Verhaltens von zwei- und dreijährigen. SOEPpapers 116.

Schwarz (1999). Self-reports. How the Questions Shape the Answers. American Psychologist 54 (2), 93-105.

Sparrow, S. S., D. V. Cicchetti, and D. A. Balla (2005). Vineland Adaptive Behavior Scales: Survey Forms Manual. (Second Edition ed.). Circle Pines, MN: American Guidance Service.

Statistics Canada (2001). National Longitudinal Survey of Children and Youth.

TNS Infratest Sozialforschung (2015). SOEP 2015 - Erhebungsinstrumente 2015 (Welle 32) des Sozio - oekonomischen Panels: Mutter und Kind (2 - 3 Jahre), Altstichproben. SOEP Survey Papers 278. Berlin: DIW/SOEP.

Tylenda, B., J. Beckett, and R. P. Barrett (2007). Assessing mental retardation using standardized intelligence tests. In J. Matson (Ed.), Handbook of Assessment in Persons with Intellectual Disability. London, Amsterdam, Oxford, Burlington, San Diego: Elsevier.

Wagner, G., J. Frick, and J. Schupp (2007). The German Socio-Economic Panel Study (SOEP) - Scope, Evolution and Enhancements. Schmollers Jahrbuch 127(1), 139169. 


\section{Figure A1: SOEP Screening Questionnaire}

12 For parents, it is always a big event when their child learns something new. Please tell us what those new things were in your child's case. Speaking:

Speaks in full sentences (with four or more words) Follows instructions, five minutes after hearing them. Can state his/her first and last name if someone asks for it. Listens attentively to a story for 15 minutes or longer Passes on simple messages such as "dinner is ready" Everyday skills:

Uses a spoon to eat, without assistance and without dripping Blows his/her nose without assistance Uses the toilet to do "number two" Put on pants and underpants the right way around Brushes his/her teeth without assistance Movement:

Walks forwards down the stairs

Climbs up playground climbing equipment and other high playground structures

Cuts paper with scissors

Paints/draws recognizable shapes on paper

Can hold a pencil correctly

Social relationships

Participates in games with other children

Gets involved in role-playing games ("playing pretend")

Shows a special liking for particular playmates or friends

Is able to name his/her own feelings, e.g., "sad", "happy", "scared"

Takes turns when playing playing without being asked.

\begin{tabular}{|c|c|c|}
\hline Yes & Partly & No \\
\hline 1 & 2 & 3 \\
\hline 1 & 2 & 3 \\
\hline 1 & 2 & 3 \\
\hline 1 & 2 & 3 \\
\hline 1 & 2 & 3 \\
\hline
\end{tabular}

\begin{tabular}{|c|c|c|}
\hline Yes & Partly & No \\
\hline 1 & 2 & 3 \\
\hline 1 & 2 & 3 \\
\hline 1 & 2 & 3 \\
\hline 1 & 2 & 3 \\
\hline 1 & 2 & 3 \\
\hline Yes & Partly & No \\
\hline 1 & 2 & 3 \\
\hline 1 & 2 & 3 \\
\hline & & \\
\hline 1 & 2 & 3 \\
\hline 1 & 2 & 3 \\
\hline 1 & 2 & 3 \\
\hline & & \\
\hline Yes & Partly & No \\
\hline 1 & 2 & 3 \\
\hline 1 & 2 & 3 \\
\hline 1 & 2 & 3 \\
\hline 1 & 2 & 3 \\
\hline 1 & 2 & 3 \\
\hline
\end{tabular}

